\title{
TEACHING AS A POLITICAL ACT: THE ROLE OF CRITICAL PEDAGOGICAL PRACTICES AND CURRICULUM
}

\author{
CHETAN SINHA
}

\begin{abstract}
The present paper is an inquiry into the role of the teacher in the context of the dominant Indian value system, an imposed curriculum and teacher-students interactions from the social psychological and critical interdisciplinary perspectives. The role of the school in the present modernist worldview is to frame and impart knowledge which may lead to economic growth. In this context, the role of the teacher is observed as being limited to a bearer of information rather than a leader who visualizes change and develops critical ability among students. Based on the theoretical framework of postformalism and collective/social identity, the current work argues that the role of the teacher is not limited to passively following and communicating mainstream values but involves constructing a new participative identity through critical pedagogical engagement and by acting as an active agent of social change.
\end{abstract}

Key words: teacher-student relationship; critical pedagogy; hidden curriculum; identity; India.

Much of the discussion in educational debates in India has been based on norms that assume teachers uncritically follow the established value system. This does not reflect the socially constructed process that politically shapes teachers' behavior. The expression of teachers' beliefs and sociocultural experiences in the classroom has rarely been acknowledged in formal education (Myers, 2009). The critical pedagogical discourse highlighting teachers' sociopolitical experiences and social identity has found less space in mainstream policy making. In fact, there has been little examination of the context in which teaching practices are shaped and the extent to which it corresponds to the identities which help students identify with the educational domains. This has resulted in the reinforcement of stereotypes and stigmatization in the educational domain based on student identity and has led to student disidentification (see Steele, 2010). As Smith et al. (2005) have argued much of the focus on teachers' learning has emphasized formal subject knowledge (e.g., Shulman \& Shulman, 2004) rather than teachers' relevant life experiences and informal learning outside school. The aim of this article is to understand the role of the teacher as a facilitator enabling social change by developing critical consciousness among students. This article is based on the premise that teacher-student collaboration is the result of sociocultural matching and a process of social identification where the teacher acts as an agent of collective struggle striving to cultivate a 
common identity for social change. However, the tendency of the individual to see oneself as an authentic representative of identity may lead to an end to the nurturing of diverse values. The point being argued here is that the teacher's role should be seen to nurture diversity and not propagate a dominant identity in the name of a global identity.

Teaching-learning processes in India are mostly based on one-way interaction between teachers and students, where it is assumed the authoritarian work style of the teacher fosters leadership ability among the students (see Chamundeswari, 2013). Sometime teachers engage in coercive methods to deal with students. There have been a number of incidents where teachers' behavior in the classroom has caused students to dropout. These dropouts occurred because low-status students belonging to a lower caste and class background perceived they were being discriminated against. Many observations and studies have reported caste-based discrimination among Dalit students (the historically oppressed and low status group who are conscious of their caste identity) in India, with students being made to sit and eat separately in schools and face psychological humiliation from upper-caste peers and teachers (see Jogdand, 2015; Nambissan, 2009; Sharma, 2015). In India, the caste-based social structure has played a major role in educational settings. Caste cannot be reduced simply to the available structural hierarchies such as that which distinguishes between Brahmins, Kshatriyas, Vaishyas and Shudras, for example, but has deeper connotations concerning position on the social ladder (see Jodhka, 2015). This perception of a person's on the social ladder has created many divisions and inequalities in society, especially in the educational context (see also Sinha, 2016, in press). It is also observed that teachers' and students' representations of academic achievement and failure differ in an Indian context (see also Sinha \& Mishra, 2015). Awareness of the importance of societal structure in the present educational context and how people identify with the social structure plays a major role in understanding the available interaction pattern and can also act as a catalyst to cross the boundary in pursuit of better social mobility and change.

Historically the approaches to educational reform were teacher-student discourses under the dominant paradigms of transformation. This neglected the subtle dynamics which shaped the experiences and created many divergent viewpoints (see also Billig, 1987). Thus, veracity of knowledge is also decided on the basis of communication processes whereby teachers authenticate the knowledge. It is assumed that the validity of any system of knowledge was inferred from the identity of the teacher-student discourses. However, it has also been observed from ancient and contemporary texts that knowledge building and authenticating processes depend upon teachers and students identifying with the dominant value system. So, it also depends upon the situational and sociopolitical context in which the value, emotions and awareness of the available knowledge are constructed. Thus, the reification of knowledge and the emerging consequences, such as inequalities, stereotypes, prejudices, discrimination and aggression have left little room for the other possibilities brought by having an understanding of the knowledge and theory for the same observable phenomenon. For example, the compulsory inclusion of Hindi language (derived from Devanagari Script and spoken in most of northern India) in the course curriculum across the Indian States, despite the states having different mother tongues, created much protest across India against the dominance of one language. This was perceived as a bias against the children's sociocultural experiences. There has been some flawed analysis of teachers' practices in diverse cultural 
and political settings, for example, on pedagogical practices in India as a marker of the gurushishya (teacher-student) relationship, where this has been exaggerated as the only act of deference and purity and not as identification with values. This relationship between teacher and students also operates in a power context where identity dynamics nurture a hierarchical relationship in which one ideology is eulogized in the name of authentic knowledge and cultural adaptations.

The rhetorical process, begun during the pure Sophist tradition affected the basic nature of teaching and many of the inferences made were just the persuasive effects of language. The different philosophical schools that explain the context within which education is conducted, such as empiricism, rationalism, constructivism and social constructivism have not interacted in such a way that they might provide a common platform for understanding the issues of inequality in education. Schools of thoughts and metatheories that support western capitalism in modern society have a marked impact on the educational system. Since contemporary thinkers consider collaborative interaction between teacher and students to be ideal, the stratification of the Indian society in terms of caste, social class, gender, religion and so on has only featured in statistical analyses and has not been subjected to active experiential analysis. Researchers suggest that corresponding methodological approaches such as critical ethnography, the collaborative narrative building approach or experimental understanding can be used to capture the current educational scenario. Here teacher and students do not passively adapt to the curriculum but to creative human beings who cognize and rationalize the curriculum, develop pedagogies catering to the need of diversity and engage in critical activities. As teachers are the product of society, they are not beyond prejudice and thus need to be critically conscious of their prejudiced self, formed by society, and engage in dialogue with students to protest against culturalism and conformity to a dominant ideology which has led to various prejudices. In a research article, Leix (2015) reported that multicultural education places demands on teachers' beliefs, attitudes and prejudices which influence students' beliefs and multicultural competence. Hence, the meaning of education is co-constructed together by teachers and students, where teachers' understanding of diverse identities becomes the dominant marker of student representations. However, teachers have the potential to develop student ability to raise critical points, to go beyond the established paradigms of science, to cross the boundary of laboratory-based understanding and connect with society using an evidence-based approach. For example, the development of critical consciousness among computer science students enables them to connect with the societal culture and develop their understanding of the meaning and dominance of technology for those who cannot afford to access it.

It has been reported that the middle classes in India were very receptive to the western values of enlightenment and modernity (e.g. Harriss, 2008), where it was assumed social challenges were to be tackled with the help of modern education without giving in to the oppressive rationalities of traditional discourse on caste, class and gender issues in India (see Fernandes \& Heller, 2008). The modernity that had its hold on the mindset of educators became a mode of production for a tool for the progressive future society. So, science's methodological assumptions and the urge to search for objectivism had an important impact on teachers' values, leading them to be swayed more by the dominant discourse as a means of survival. The current article does not explore the assumptions of modernity as many 
teachers have but moves away from the norms of conformity and calls for a social change in which the teacher's pedagogical style, language use and interaction with students could be combined to create a conscious mode of persuasion, a kind of politics which teachers could use to persuade and mark out their identity as teacher. The concern here is to consider the nature of that persuasion and the tools and intentions which drive the interactional processes and reflect on whether they constitute a system that is pro-social change or antisocial change. There is a paradox of intention since at times teachers politicize their acts to persuade students and at others affirm the conformist discourse and status quo. As has been reported in some of the studies on values and action, the psychological consequences are that people in individualistic and collectivistic cultures feel dejected when their embedded values are violated but show a more promotion focus in an individualistic culture than in a collectivist culture like India, where the promotion and prevention focus go together (see Higgins \& Spiegel, 2004). Beliefs about the self in terms of society's aspiration and prescription play a very important role in terms of the match and mismatch of values held by teachers and students, leading to the mobilization of matching social categories for different ends. Studies show that the teacher acts as a mediator linking the values of that society with the individual values of the students and engaging in new meanings which leads to novel understandings. However, the problem is this understanding is not confined to the positive, for example, to social justice but may lead to the reification of stereotypes and prejudices. One of the studies on the risk of caste-based stereotypes emphasized the situational priming of the ability stereotype among low caste students in an evaluative context (Hoff \& Pandey, 2006). However, when the value is altered through instructional manipulations the effect of the stereotype threat among ability stereotyped low caste students can be managed. The Indian context is believed to be a collectivist one in which values are interdependent and connected but this forms the basis of the individual's identity in any sociopolitical context. It was observed that the Indian context is driven by the dominant values of caste, class and gender, leading to rigid stratifications in which the hierarchy of values can be felt in family and work contexts.

\section{Legitimacy in education and practice}

The present educational system has legitimized its mainstream ideology which inadvertently deprives groups portrayed as unconventional or belonging to a different background of their rights. However, including the widely debated ideology in mainstream education as a new approach was untenable as it was seen as unthinkable and oppressive on the part of victims. For example, the inclusion of different theoretical models in national educational programs without any understanding of the metatheoretical assumptions of these approaches may limit the agenda for open and democratic forms of education. Thus, pedagogy and the role of the teacher as leader for change are limited by the structure shaped by the social categories dominating the social, economical and cultural artifacts. Turning to the meaning of legitimacy of institution and the broader social systems, under which the teacher's role seems to be manipulated, it is imperative that we go beyond the present philosophy of empiricism and see the identity of the teacher as part of a global movement seeking social change and respecting diverse forms of expression and representations. 
In explaining legitimacy, psychologists French and Raven (1959) referred to it as a social influence induced by feelings of "should," "ought to," or "has a right to," i.e., by appeals to an "internalized norm or value." This has been observed in teachers' approaches where the actions of the teacher embedded in the mainstream and dominant caste and class structure, and an opposing awareness of the diversity issues, have created greater cognitive load leading to a subtle rejection of alternative voices in the classroom. However, the ambivalence of teachers from different backgrounds is neither representative nor even part of the mainstream value systems. This ambivalence has been expressed in two forms of behavior, either as a carry-over effect in terms of accepting authority or in terms of becoming separated from the domain. Suchman (1995) argued that "legitimacy is a generalized perception or assumption that the actions of an entity are desirable, proper, or appropriate within some socially constructed system of norms, values, beliefs and definitions" (p. 574). Referring to legitimacy as "authorization," Kelman and Hamilton (1989) argued that when an authority is legitimate, "the duty to obey superior orders" replaces personal morality, with people allowing legitimate authorities to define the boundaries of appropriate behavior in a given situation ( $\mathrm{p}$. 16). Or, more simply, legitimacy is the perception that one "ought to obey" another (Hurd, 1999). Hence, legitimacy is an additional form of power that enables authorities to shape the behavior of others distinct from their control over incentives or sanctions (Ford \& Johnson, 1998, French \& Raven, 1959). Therefore, the construction of educational artifacts such as curriculum and pedagogy absorbed legitimate content, as expressed in the sociopolitical discourses, thus tapping into the roots of the prevailing constructivist paradigms. However, there are some observations in the critical pedagogy traditions that have gone beyond constructivism to include social content highlighting critical issues pertaining to the sociocultural aspects of teacher and student engagement (see Kincheloe, 1993, 2004).

In the context of the legitimacy of mainstream pedagogy which seems to be hegemonic in its discourse, Giroux (2010) asserted that critical pedagogy provides the context for generating a critical thinking ability among students that goes beyond the fear of consequences, and is reflective of and reflexive towards the knowledge the students gain and the obligations they have in terms of social responsibility. Critical pedagogy recognizes that pedagogy is not about passively receiving (often empirically based) information but about engaging in a dialectical process of gaining a better understanding of the social issues from a multicultural and diversity perspective (see Banks \& Banks, 2010; John-Steiner \& Mahn, 1996; Mayo, 2013). In contrast to this pedagogy of conformity and disinvestment in public education, postformalists such as Kincheloe (1999; 2004) encourage teachers to adopt a critical pedagogy as an agent of change by expanding the imagination and the appropriation of knowledge in the form of self-reflection and self-determination, and thus collectively and critically shaping the larger social order.

Critical pedagogy recognizes that the standardization of curricula, knowledge, teaching and social relations does an injustice to the multiple and varied narratives, issues, histories, and experiences that students bring to schools and that operate in classrooms within different cultural, economic and political contexts. This is a pedagogy that begins from an understanding of students as individuals with enormous capacities to be critical, knowledgeable and informed citizens, workers and social agents. The critical pedagogical approach evident in the work of John Ogbu and Joe Kincheloe (see Sinha, 2016) seems to 
have ample potential to help students from diverse ethnic and class backgrounds to engage in the classroom process with the help of teachers, without the feeling of acting White and without disengaging their self from educational domain (see Freire, 1970; Gallagher, 1999; Kaščák et al., 2012; Kincheloe, 1999). Consequently, schools and the presence of a teacher are viewed as crucial resources in a developing democracy, and teachers are valued as the front line of professional workers responsible for educating young people in the ideals, goals, and practices of a sustainable democratic society.

\section{Contextualizing the role of teacher}

The act and philosophy of teaching are not contextual processes and are driven by the situations, cultural backgrounds and sociopolitical factors regulating the institutions. Some major aspects of identity, as emphasized by Ogbu (2003), that is, voluntary and involuntary identities, have a major impact on the teaching and learning processes. For example, the involuntary aspects of caste or gender or both in teacher-student interactions and relationships (see also Myers, 2009) and social class divisions and the impact they have on the teaching-learning process or other factors such as religion, region and languages are important contexts that should be looked into. The present article attempts to locate the pedagogical vehicle in the conscious activity of the teacher, who is believed to shape student awareness and knowledge and develop critical abilities. Thus, it has been questioned as to whether the task of the teacher is limited to teaching the curriculum or going beyond it and highlighting underrepresented issues in the educational system through activism and social action. Attempts to understand the teacher's role in situating the teacher-student relation in the wider social context of multiculturalism is well reflected in the philosophy of critical pedagogy. From the perspective of philosophy of education, where questions are raised and the nature of knowledge is directed, the focus is on investigating the history which has shaped teaching methods and their political intentions. The basic tenets of the psychology of education, philosophically derived from the school of empiricism and especially from behaviorism, have limited it to shaping student behavior in accordance with the prevailing mainstream value system, rather than encouraging it to develop the freedom to raise critical points. In this context, teachers were found to be the representative voice of the dominant discourses of the dominant identities, for example, social class, which overemphasized ability, meritocracy, authority etc., and paid less attention to sociocultural experience (Vygotsky, 1978), the development of critical ability and problems associated with the social structure and curriculum.

\section{Critical pedagogy and hidden curriculum}

The framing of the curriculum and the teacher's role as mediating between the acquisition of textbook knowledge and what goes on in the classroom has been a contested issue. Teachers, it seems, have been looked on as passive elements representing the dominant values of society, but it is also imperative to understand that teachers have a much larger role in bringing about social change in terms of facilitating critical consciousness among students. Teachers are educational leaders and their sociocultural experience and consciousness 
may not correspond to the students' consciousness but the context in which teaching and learning occurs provides ample potential for a critical environment to develop where a common consensus can be built. This is not to oversimplify the fact that teachers are the most important element in social transformation nor that humans have struggled to answer a basic question-what is the meaning of education?-since primordial times. School teachers in India are positioned on the lower rungs of the social class ladder, and teachers from lower status backgrounds in government schools are also often the victims of discrimination. Their role is limited to facilitating rote learning, and they are not paid enough to perform other activities, including buying and reading books. It has been observed that teachers and students from lower status backgrounds are susceptible to many kinds of stereotypes and prejudices, and are categorized as passive followers of the mainstream curriculum. There are also hidden curriculums, which rarely come in real tangible forms, and hidden biases, stereotypes and prejudices and many other things that remain invisible in terms of policy making and curriculum design. The hidden curriculum has been linked to teachers and their critical pedagogical style. There have been instances where students from lower caste backgrounds have become the victims of discrimination in school through various curricular sources, such as the mathematics syllabus where they are ability stereotyped (e.g. Hoff \& Pandey, 2006). They have learned and internalized negative ability stereotypes about their social group and these have been associated with the mathematics curriculum. Teachers have a major role to play in crossing the boundaries of these kinds of stereotypes and they can either concretize the stereotype or help students to cross the barriers of these deepseated stereotypes by ensuring an inclusive classroom environment. In his Pedagogy of the Oppressed, Paul Freire (1970) called for a new kind of education which would create an empowering partnership between the teacher and the students through active dialogue and humanization processes.

Teachers are to be considered agents of social change and with the help of the curriculum they give new meaning to the social psychological discourse rather than simply endorsing the cultural legitimacy. For example, some of the work conducted in an Indian context has shown that teachers are the carrier of cultural resources in both a positive and a negative light (see Gupta, 2006). Teachers' pedagogical styles may vary because of the changes they encounter in the classrooms in terms of student diversity (see Ogbu, 1992). Their expectations thus undergo tremendous cognitive load and teachers sometimes find themselves succumbing to bias. These biases, for example not paying attention to students from lower status backgrounds, scolding, beating or giving fewer marks, are practices which may emerge due to the disconnect between expectation and the teachers' own sociocultural experiences. Thus, the sociocultural imperatives are the result of a legitimate endorsement of beliefs and values which are not truly scientific but loaded by larger social structures, like social class, caste, gender roles, linguistic propensities etc. There are other cases in which teachers from diverse backgrounds have not been well accepted by the authorities and students from the dominant value system. However, it is rare for teachers from oppressed identity groups to deal with students with socially privileged identities. Most teachers from lower social class backgrounds deal with children from the same social class background. For example, recently Tukdeo and Babu (2015) have highlighted the regimented work conditions of teachers in Aanganwadis (courtyard shelter meant to take care and educate children and families in 
health and non formal preschool activities) and depicted the reality of restrictions imposed on teachers contrary to the envisioning philosophy which drives the real teaching task. The point of contestation here is that the teacher's role has been reduced to that of bearer of information and not as a leader who should have the vision to highlight critical points and work on collaborative elements for social change (sees also Sinha, 2013a).

The basic teaching agenda has been hindered as the social structure has legitimized the continuity of differences based on caste, class and gender. In other words, the role of the teacher and pedagogic intervention generally has not highlighted the hidden nature of the curriculum and has buffered critical viewpoints of the divisions in society. The teaching agenda has more or less been reduced to legitimizing identity and its sociocultural manifestations (Sinha, 2013b). Attempts to cross the boundaries of oppressed identities based on the contingencies of caste, class and gender have more or less been resisted or have generally not been debated in mainstream school culture (see also Deshkal report, 2010). Dalit scholars in India have found that the social space, including the educational domain, is humiliating and historically exclusive, and shifts from the subtle to the blatant (e.g. Guru, 2009). The lived-in experience of students and teachers from oppressed backgrounds reveals the victimization that has occurred historically in educational discourses where higher status identities have rejected another person's identity. There is therefore a need for individual identities to be asserted to ensure social mobility and consciousness raising to regain selfesteem, and is only possible if oppressive politics is rejected and a new kind of emancipatory politics is adopted (see Reicher, Jogdand, \& Ryan, 2015). However, social identities play an important role when there is mutual interaction between identities in the shared space which is not yet the reality but is slowly turning into subtle discrimination and microaggression as a result of the open political participation and self-assertion of oppressed groups.

The curriculum and teachers' pedagogical styles intersect implicitly at the point where minimum learning happens. For example, Srinivasan (2015) has critically highlighted the issue of quality learning in schools under the supervision of higher administrative bodies, where the curriculum load is greater, and the role of education is one of memorization and rote learning only. This information overload is more visible now, and students and teachers find themselves under increasing pressures. The freedom to bring about social change and identify issues of social justice in the culture is under the strict control of the bureaucratic logic. Hidden curriculums containing particular forms of knowledge, culture, values, and desires are taught but never talked about or made public (see also Bergenhenegouwen, 1987). One only has to mention as a case in point the ways in which schools increasingly function as part of a power circuit that produces a school-to-prison pipeline (Giroux, 2010). Critical pedagogy provides the conditions under which students can think critically, take risks, and reflect on the connections between the knowledge they have gained and the obligations of civic and social responsibility while recognizing that pedagogy is not about passive reception (often empirically based). In opposition to this pedagogy of conformity and disinvestment in public education, the critical pedagogy encouraged by the postformalists expands the imagination and leads to the appropriation of knowledge in the form of self-reflection and self-determination, thus collectively shaping the larger social order. In this context, Giroux (2010) suggests that any form of transformative pedagogy can be viewed as dangerous by the established system. 
Critical pedagogy is also about recognizing the importance of different contexts and how these affect the conditions for teaching and for interacting with students. Not only is it context sensitive, critical pedagogy recognizes that the standardization of curricula, knowledge, teaching and social relations does an injustice to the multiple and varied narratives, issues, histories, and experiences that students bring to schools and that operate in classrooms within different cultural, economic, and political contexts. This is a pedagogy that begins with an understanding of students as individuals with enormous capacities to be critical, knowledgeable and informed citizens, workers and social agents. From the viewpoint of Giroux (2010), it can be inferred that critical pedagogy completes the missing link between formal and postformal education.

The texts are considered to contain the knowledge the discipline wishes to transmit to figure generations; as Kuhn says, they are "pedagogic vehicles" (1970, p. 137). This mode "reading" fits the "transmission model" or "banking" notion of education (Freire, 1970). From the critical perspective, texts are seen as the social constructions of members of a particular scientific community embedded in a particular meaning-making system, that is, as an ideological inheritance (Gallagher, 1999, p.71). Texts are positioned in a web of other texts, in other words, they have political, historical and social contexts (Gallagher, 1999, p.71). This is called intertextuality' (Scholes, 1985). However, positive results have been obtained when the method of 'reciprocal teaching' is applied in shared endeavor between student and teachers where questioning, clarifications, summarizing and predicting strategies are used to construct text-based knowledge (John-Steiner \& Mahn, 1996). According to McLaren (1998), it is imperative for teachers to engage in the critical and revolutionary pedagogic perspective by developing critical consciousness among students. In some postcolonial contexts, the issues of identity politics have raised immense discussion among people about the issues of representations and created subtle divides.

In an Indian ethnographic work, Sarangapani (2003) found that children's use of cultural artifacts in their ecological setting was not reflected in the textbooks they encountered in the classroom. However, the use of artificial signs and symbols was evident in formal classroom setups (Sarangapani, 2003), making them more vulnerable to the natural process of education. The effects of colonization and the model of education sustained throughout history created a mechanistic outlook on education and the teacher-student relationship. In this context, Adams et al. (2015) have expressed the need to decolonize the mindset and invite us to see the diverse perspectives across the entire domain which has an important role to play in the politics of social change. Thus, the task of teachers as leaders of positive change is to help develop discourses that can raise and articulate the issues of identity in education (Giroux \& McLaren, 1992) and the need for a social movement in an educational domain where the issues of marginalization in education (Sleeter et al., 2012) are clearly understood both at the level of critically conscious discourses and at the level of the practices of teachers and educators.

One example Kasten (1992) provides concerns the high dropout rate among Native American children caused not by their having a physical or learning disability but by the incongruence between the Native American value system and the mainstream American educational system. In a similar context, Tandon (2000) highlighted an anti-colonial, grassroots and ecologically sensitive approach in Indian educational context. However, the 
importance placed on curriculums that represent the cultural values denoting dominant value systems and their compatibility with teachers' educational experiences overlooks aspects of underrepresented identities. The need arises for an active re-categorization of social categories in the Indian educational context (Gillespie, Howarth, \& Cornish, 2012). For example, the match/mismatch between teacher and student identities could be transformed if teachers were to transcend their hierarchical roles and merge their identities with student identities to empower participation.

Sleeter and Stillman (2005) emphasize a pluralistic form of education which includes cultural and historical respect for the entity involved in the learning processes. This includes curricula and pedagogies which are compatible for all students from diverse backgrounds, historical roots and cultures. These students will find they use different tools to supplement their cognitive processes when dealing with knowledge in order to achieve the same end results with equality and equity. This form of education rejects the inflexibility in an education system based on a one-fits-all notion of state-sponsored pedagogies and helps student pursue indigenous ways (see Kennedy, 2013; Korteweg et al., 2014; Oppong, 2013) of dealing with their environment.

\section{Conclusion}

Teaching in a culturally responsive way that is critical but does not overpower diverse identities and cultural experiences is a major goal for today's serious educators in their efforts to fill the gap created by the banking system of education which is on the proposed agenda of the standardized educational system and which will lead to the same social reproductions in classrooms and in education (Collins, 2009). As group membership and identification have been found to be an important precursor to collaborative interaction in the Indian educational context, there is a need to re-categorize power identities, since healthy participatory relationships are important. Thus, it is imperative for educational reformers and teachers to encourage a new kind of diversity in which a common in-group identity and critical consciousness are created, so that all groups can identify with the learning process in the broader political discourse (see Bowskill, 2013; Tapper, 2013; for another view see Kelly, 2009). Thus, the task of teachers is to promote critical discourses and satisfy the need to produce a bricolage of experiences by integrating social identities (Sanchez-Burks, Karlesky, $\&$ Lee, 2013) and making understanding of the educational task clearer. Thus, the role of the teacher as an entrepreneur of identity and an entrepreneur of awareness and change is one of the most important voices fulfilling the agenda of education.

\section{References}

Adams, G., Dobles, I., Gomez, L. H., Kurtis, T., \& Molina, L. (2015). Decolonizing psychological science: Introduction to the special thematic section. Journal of Social and Political Psychology, 3(1), 213-238.

Banks, J. A., \& Banks, C. A. M. (2010). Multicultural education: Issues and perspectives $\left(7^{\text {th }}\right.$ ed.). NJ: John Wiley \& Sons.

Bergenhenegouwen, G. (1987). Hidden curriculum in the university. Higher Education, 16(5), 535-543. 
Billig, M. (1987). Arguing and thinking: A rhetorical approach to social psychology. Cambridge: Cambridge University Press.

Bowskill, N. W. D. (2013). A social identity approach to learning with classroom technologies. Ph.D. thesis. University of Glasgow.

Chamundeswari, S. (2013). Teacher management styles and their influence on performance and leadership development among students at the secondary level. International Journal of Academic Research in Progressive Education and Development, 2(1), 367-418.

Collins, J. (2009). Social reproduction in classrooms and schools. Annual Review of Anthropology, 38, $33-48$.

Deshkal (2010). Inclusive classrooms, social inclusion/exclusion and diversity perspectives, policies and practices. New Delhi: Deshkal Publication.

Fernandes, L., \& Heller, P. (2008). Hegemonic aspirations: New middle class politics and India's democracy in comparative perspective. In R. J. Herring \& R. Agarwala (Eds.), Whatever happened to class? Reflections from South Asia (pp. 146-165). Delhi: Danish Books.

Ford, R., \& Johnson, C. (1998). The perception of power: Dependence and legitimacy in conflict. Social Psychology Quarterly, 61(1), 16-32.

Freire, P. (1970). Pedagogy of the oppressed. New York: Herder and Herder.

French, J. R. P. Jr., \& Raven, B. H. (1959). The bases of social power. In D. Cartwright (Ed.), Studies in social power (pp. 150-67). Ann Arbor: University of Michigan.

Gallagher, S. (1999). An exchange of gazes. In J. L. Kincheloe, S. R. Steinberg, \& L. E. Villaverde (Eds.), Rethinking intelligence: Confronting psychological assumptions about teaching and learning (pp. 69-84). Routledge: New York and London.

Gillespie, A., Howarth, C., \& Cornish, F. (2012). Four problems for researchers using social categories. Culture \& Psychology, 18(3), 391-402.

Giroux, H. A. (2010). Dumbing down teachers: Rethinking the crisis of public education and the demise of the social state. Review of Education, Pedagogy and Cultural Studies, 32(4-5), 339-381.

Giroux, H., \& McLaren, P. (1992). Writing from the margin: Geographies of identity, pedagogy and power. Journal of Education, 174(1), 7-30.

Gupta, A. (2006). Early childhood education, postcolonial theory, and teaching practices in India. Balancing Vygotsky and the Veda. New York: Palgrave Macmillan.

Guru, G. (2009). Humiliation. New Delhi: Oxford University Press.

Harriss, J. (2008). Middle-class activism and the politics of the informal working class: A perspective on class relations and civil society in Indian cities. In R. J. Herring \& R. Agarwala (Eds.), Whatever happened to class? Reflections from South Asia (pp. 109-126). Delhi: Danish Books.

Higgins, E. T., \& Spiegel, S. (2004). Promotion and prevention strategies for self-regulation: A motivated cognition perspective. In R. F. Baumeister \& K. D. Vohs (Eds.), Handbook of selfregulation: Research, theory and applications (pp. 171-187). New York: Guilford Press.

Hoff, K., \& Pandey, P. (2006). Discrimination, social identity, and durable inequalities. American Economic Review, 96(2), 206-211.

Hurd, I. (1999). Legitimacy and authority in international politics. International Organization, 53(2), 379-408.

Jodhka, S. S. (2015). Caste in contemporary India. New Delhi: Routledge.

Jogdand, Y., \& Sinha, C. (2015). Can leaders transform humiliation into a creative force? Journal of Leadership Studies, 9(3), 75-77.

Jogdand, Y. (2016, January). Humiliation in classrooms: Implications and interventions for counselors. Paper presented in ICCP 2016 - Third International Conference on Counseling, Psychotherapy and Wellness, Christ University, Bangalore.

John-Steiner, V., \& Mahn, H. (1996). Sociocultural approach to learning and development: A Vygotskian framework. Educational Psychologist, 31(3/4), 191-206. 
Kaščák, O., Pupala, B., Lukšík, I., \& Lemešová, M. (2012). School cultures at risk of political and methodological expropriation. Human Affairs, 22(4), 524-538.

Kasten, W. C. (1992). Bridging the horizon: American Indian beliefs and whole language learning. Anthropology \& Education Quarterly, 23(2), 108-119.

Kelly, S. (2009). Social identity theories and educational engagement. British Journal of Sociology of Education, 30(4), 449-462.

Kelman, H. C., \& Hamilton, V. L. (1989). Crimes of obedience. New Haven, CT: Yale University Press.

Kennedy, C. P. (2013). Indigenizing student-centred learning: A western approach in an indigenous educational institution. Journal of International Education Research, 9(1), 1-6.

Kincheloe, J. (1993). Toward a critical politics of teacher thinking: Mapping the postmodern. Westport, CT: Bergin \& Garvey.

Kincheloe, J. L. (1999). Foundations of a democratic educational psychology. In J. L. Kincheloe, S. R. Steinberg, \& L. E. Villaverde (Eds.), Rethinking intelligence: Confronting psychological assumptions about teaching and learning (pp. 1-26). New York and London: Routledge.

Kincheloe, J. L. (2004). The knowledge of teacher education: Developing a critical complex epistemology. Teacher Education Quarterly, 31(1), 49-66.

Kincheloe, J. L., \& Horn, R. A. (Eds.). (2007). The Praeger handbook of education and psychology (Vol. 4). Westport: Praeger Publishing.

Korteweg, L., Fiddler, T., Bissel, A., Primavesi, L., Michelle, C., \& Moon, M. (2014). Circles of hope in indigenizing mainstream teacher education. In G. Sheppard (Ed.), Circle of hope in indigenizing mainstream teachers (pp. 20-36). Sudbury: Laurentian E-Press.

Kuhn, T. (1970). The structure of scientific revolutions. Chicago: Chicago University Press.

Leix, A. (2015). No prejudice-free society means no prejudice-free teachers, but better times are coming: Teachers and cultural diversity. Human Affairs, 25(3), 302-316.

Mayo, C. (2013). Queer lessons: Sexual and gender minorities in multicultural education. In J. A. Banks \& C. A. M. Banks (Eds.), Multicultural education: Issues and perspectives (pp. 209-228). NJ: John Wiley \& Sons.

McLaren, P. (1998). Revolutionary pedagogy in post-revolutionary times: Rethinking the political economy of critical education. Educational Theory, 48(4), 431-462.

Myers, J. P. (2009). Learning in politics: Teachers' political experiences as a pedagogical resource. International Journal of Educational Resource, 48(1), 30-39.

Nambissan, G. B. (2009). Exclusion and discrimination in schools: Experiences of Dalit children. Working paper series: Indian Institute of Dalit Studies and UNICEF, 1 (1), 1-30.

Ogbu, J. U. (1992). Understanding cultural diversity and learning. Educational Researcher, 21(8), 5-14.

Ogbu, J. (2003). Black American students in an affluent suburb: A study of academic disengagement. Mahwah, NJ: Lawrence Erlbaum Associates.

Oppong, S. (2013). Indigenizing knowledge for development: Epistemological and pedagogical approaches. Africanus, 43(2), 34-50.

Reicher, S., Jogdand, Y., \& Ryan, C. (2015). Political participation is self-interest...but not in the way you might think. In N. Manning, (Ed.), Political (dis)engagement and the changing nature of the 'political' (pp. 217-238). Bristol: Policy Press.

Sanchez-Burks, B., Karlesky, M. J., \& Lee, F. (2013). Psychological bricolage: Integrating social identities to produce creative solutions. In C. Shalley, M. Hitt, \& J. Zhow (Eds.), Oxford handbook of creativity, innovation and entrepreneurship (pp. 93-102). UK: Oxford University Press.

Sarangapani, P. M. (2003). Constructing school knowledge: An ethnography of learning in an Indian village. New Delhi: Sage Publications.

Scholes, R. (1985). Textual power. New Haven: Yale University Press.

Sharma, S. (2015). Caste-based crimes and economic status: Evidence from India. Journal of Comparative Economics, 43, 204-226. 
Shulman, L. S., \& Shulman, J. H. (2004). How and what teachers learn: A shifting perspective. Journal of Curriculum Studies, 36(2), 257-271.

Sinha, C. (2013a). Conceptualizing educational leadership: Does exploring macro-level facets matters? Asia Pacific Education Review, 14(2), 141-150.

Sinha, C. (2013b). The sociocultural psychology as a postformal theory of academic achievement: An interrogation into the legitimacy of formal education. International Journal of Educational Psychology, 2(2), 221-242.

Sinha, C., \& Mishra, A. K. (2015). Social representations of academic achievement and failure. Psychological Studies, 60(2), 160-169.

Sinha, C. (2016, in press). Postformalist explanation of academic achievement: Exploring the contributions of John Ogbu and Joe Kincheloe. Journal of Pedagogy, 7(2).

Sleeter, C., \& Stillman, J. (2005). Standardizing knowledge in a multicultural society. Curriculum Inquiry, 35 (1), 27-46.

Sleeter, C., Upadhyay, S. B., Mishra, A. K., \& Kumar, S. (Eds.). (2012). School education, pluralism and marginality: Comparative perspectives. New Delhi: Orient Blackswan.

Smith, K. A., Sheppard, S. D., Johnson, D. W., \& Johnson, R. T. (2005). Pedagogies of engagement: Classroom-based practices. Journal of Engineering Education, 1-15.

Srinivasan, M. V. (2015). Reforming school social science curriculum in India: Issues and challenges. Economic \& Political Weekly, L(42), 52-58.

Steele, C.M. (2010). Whistling Vivaldi: How stereotypes affect us and what we can do. New York: W. W. Norton \& Company.

Suchman, M. C. (1995). Managing legitimacy: Strategic and institutional approaches. Academy of Management Review, 20(3), 571-610.

Tandon, R. (2000). Civil society, adult learning and action in India. Convergence, 23(1-2), 120-137.

Tapper, A. J. H. (2013). A pedagogy of social justice education: Social identity theory, intersectionality, and empowerment. Conflict Resolution Quarterly, 30(4), 411-445.

Tukdeo, S. \& and Babu, S. S (2015). Teachers' work and teachable moments in the new regime. Economic \& Political Weekly, 50(12). http://www.epw.in/node/130816/pdf

Vygotsky, L. S. (1978). Mind in society: The development of higher psychological processes. In M. Cole, V. John-Steiner, S. Scribner, \& E. Souberman (Eds.). Cambridge, MA: Harvard University Press.

Christ University,

Hosur Road,

Bangalore, Karnataka,

560029

INDIA

E-mail:sinchetan@gmail.com 